\title{
Waste bio materials based viscosity reduction and rheological properties of crude oil
}

\author{
Salam K. Al-Dawery ${ }^{1}$ Saleh K. Al-Shereiqi ${ }^{1}$
}

Received: 25 September 2018 / Accepted: 8 January 2019 / Published online: 14 January 2019

(c) The Author(s) 2019

\begin{abstract}
The effectiveness of using waste bio materials as viscosity reducing agents was investigated on light and heavy crude oils of Oman. The selected materials are fiber of palm tree, date palm kernel and walnut shell. The utilization of waste bio materials is not only considered as a cost effective, but, environmentally friendly and has less effect on crude oil processing as compared to that of chemical additives. In this study, special piping structure was constructed to measure flowabilty time of crude oil. It was observed that use of bio materials reduced oil flowability time by range of $42-50 \%$ using particle size $75 \mu \mathrm{m}$ and by $66 \%$ using particle size $150 \mu \mathrm{m}$. Moreover, the effect of different additives and various concentrations of bio materials on oil rheological properties, for instance viscosity and yield stress, were also studied. Results showed that the light crude oil exhibits a non-Newtonian viscoplastic behavior following (Bingham plastic model) whereas the heavy crude oil exhibits a non-Newtonian pseudoplastic behavior (shear thinning model). The use of bio materials reduced the limiting viscosities of the light crude oils by $62 \%$ using particle size $75 \mu \mathrm{m}$ and $75 \%$ using particle size $150 \mu \mathrm{m}$. However, limiting viscosity of heavy crude oil was reduced by $15 \%$. In addition, it was observed that using bio materials lowered yield shear; light crude reduced by average $32 \%$ while heavy crude oil reduced by $10 \%$.
\end{abstract}

Keywords Crude oil rheology $\cdot$ Waste bio materials $\cdot$ Viscosity reduction $\cdot$ Non-Newtonian model

\section{Introduction}

Crude oil is a complex mixture of hydrocarbons containing aromatics, saturate, wax, resins, sulfur, oxygen, nitrogen, etc, ranging from light hydrocarbon compounds such as methane to large hydrocarbon molecules such as asphaltenic compounds (Al Beshara et al. 1987; Speight 1998; Wardhaugh and Boger 1991). The chemical variations of the crude oil have a large impact on the viscosity of crude oil, ranging from 0.1 to $100 \mathrm{~Pa}$ s which could result in non-Newtonian behaviors (Nunez et al. 1991; Ghannam and Esmail 2006). The viscosity has an important role in pipeline design and operation, i.e. a higher viscos fluid leads to a higher pressure drop. Fluid shearing and stress at the wall of the pipeline leading to a higher pressure drop.

Transportation of heavy crude oil suffer from pressure drop in the pipeline over a long distance. As a result, high

Salam K. Al-Dawery

salam@unizwa.edu.om

1 University of Nizwa, Nizwa, Oman viscosity causes losses in the applied pumping energy. Different polymers were investigated and used as viscosity reducing agents since 1948 (Manfield et al. 1999; Fu and Kawaguchi 2015; Abd et al. 2014; Hart 2014).

Drag can be defined as the amount of pressure loss due to friction of turbulent flow inside the pipelines leading to more energy being supplied for pumping and transportation of crude oil. The relationship between friction factor and Reynolds number as proposed by Blasius equation (Trinh 2017) as

$f=\frac{0.079}{\operatorname{Re}^{0.25}}$.

As the fluid velocity is considered to be a main term in Reynolds number, as well as an essential term in friction factor relationship. Therefore, both fluid velocity and Reynolds number are affecting the pipe pressure drop. From above, it can be stated that longer the pipeline, the higher the pressure drop, states as:

Pressure $\operatorname{drop}(\Delta \mathrm{p})=$ function offlow performance of crude oil.

Nizwa, Oman 
Viscosity reduction of heavy crude oil for pipeline transportation is essential for suppressing and stabilizing turbulent eddies and breaking laminar layer. Various techniques are used for reducing the required energy for pumping, and hence, increasing pumping efficiency and enhancing the flow performance of the crude oil through the pipeline (Ram et al. 1967; Langevin et al. 2004; Drappier et al. 2006; Hemant and Bharambe 2006; Ashrafizadeh and Kamran 2012). Such techniques include surfactants, dilution with lighter crudes such as hydrocarbon gas and alcohol, heating, formation of oil-water emulsion, etc. However, some of these approaches are not practical such as heating over long distance from oil reservoir to refinery (Ashrafizadeh and Kamran 2012). Similarly, difficulties of using chemicals for viscosity reduction arise during their recovery from crude oil; dissolving in heavy oil; determining the optimum dosage, and thus maintaining optimum pressure drop. For example, the use of polymer additives such as poly-isobutylene of high molecular weight diluted with kerosene was tested as drag reduction by Ram et al. (1967) which indicated that the friction coefficient was remarkably reduced. Similarly, the synthesized chemical of esterified copolymers with fatty alcohol was prepared and used as additive to Indian crude oil for drag reduction and pour point depression. The results showed an improvement in the flow properties (Hemant and Bharambe 2006). Moreover, the effectiveness of using polyacrylamide as additive for drag reduction was investigated by Khadom and Abdul-Hadi (2014) which indicated that increasing polymer concentration increased drag reduction factor. The turbulent flow statistics were examined using superflac-A110 as drag reduction polymer (Chemloul 2014). It was observed strong decrease in velocity fluctuations and low turbulent shear stress.

Similarly, several researchers have demonstrated the use of surfactants to improve crude oil flowability (Zakin et al. 1998; Hart 2014).

Despite these attempts, application of these methods is still difficult such as break down of polymers and the reduction of working efficiency. Some of the chemicals used such as surfactants and/or polymers may have a negative impact on the environment (Pereira et al. 2013).

Nanofluid materials were used as drag reduction agents and few successful results were reported (Ibrahim et al. 2017). The obtained values of the Darcy coefficient for $100<\operatorname{Re}<10,000$ fitted the theoretical formulas and showed evidence that the additive had an influence on pressure loss (Calin 2009). The performance of using cocus nucifera fiber suspension was studied for improving flow in water pipeline, $56 \%$ in drag reduction was achieved. Samples of crude oil and water emulsions in presence of surfactants have been investigated to determine the pressure loss in pipelines and determine Darcy coefficient, $\lambda$. Both stationary and transitory flow regimes were investigated as a function of each sample's rheology (Marmy et al. 2012). $\mathrm{SiO}_{2}$ nanoparticles were used as drag reducing material in water pipeline. At the same conditions, the results indicated that drag reduction was more prominent in rough pipe than in smooth pipe (Pouranfard et al. 2014). Moreover, 24\% drag reduction was achieved. The efficiency of silca nanoparticles with cationic surfactant in rotating disc apparatus has been investigated by Akindoyo and Abdulbari (2015) which showed 50\% in drag reduction was achieved using the proposed material.

Date palms trees are grown in many countries around the world. Arab countries have an estimated 105 million date palm trees of which more than 51 million in Arab Gulf Countries (GCC) resulted in the availability of large amounts of waste biomass. The main produced biomass consists of palm leaves, barks and date seeds (Salman et al. 2016). Recent inventory of available waste biomass of date palm trees in GCC showed that more than 1.013 million tonnes palm leaves; 574.8 thousand tonnes of cull dates and 345 thousand tonnes of dates seeds available annually. Date palm leaves are the most available by-products of date palm trees due to cleaning and pruning operation that are conducted annually (Salman et al. 2016). Currently, the waste of date palm trees is either disposed of in the landfills or burned without energy recovery (El-Juhany 2010; Usman et al. 2015). A significant portion of this waste biomass could be efficiently used as viscosity reduction agents. The massive available amount of waste of date palm trees can sufficiently provide significant potential feedstock for the cost effective materials suitable for viscosity reduction of crude oil.

The goal of this work was to investigate the effectiveness using available bio waste materials such as fiber of palm tree, date kernel and walnut shell as viscosity reduction of Oman's crude oil. In addition, to investigate the impacts of these materials on viscosity and rheological properties of the crude oil. Two types of crude oils with API gravity 41.3 and 17 from Sultanate of Oman were used.

\section{Rheology}

Rheology is the science of the flow and deformation of matter under applied stress. Newtonian fluids exhibit constant viscosity which does not dependent on shear rate and fixed resistance to flow at different applied forces. NonNewtonian fluids exhibit change of viscosity with shear rate and different resistance to flow at different applied forces (Al Zahrani 1997). The addition of water-based materials modified the rheological properties of the fluid. Investigation conducted by Benslimane et al. $(2013,2016)$ using pipe flow of bentonite clay and mixtures containing $5 \mathrm{wt} \%$ of bentonite and 0.1 and $0.5 \mathrm{wt} \%$ of carboxymethyl cellulose. Their results showed that the bentonite suspension exhibited shear thinning rheological behavior as described by the 
Herschel-Bulkley model. In addition, they concluded that the bentonite suspensions showed small drag reduction while the blends of clay-polymer exhibited much more effects. The Non-Newtonian fluid can follow one of the models below:

Shear thinning with initial yield stress (thixotropic), $n<1$.

Shear thickening with initial yield stress (rheopactic), $n>1$.

Bingham plastic (viscoplastic), $n=1$.

Shear thinning (pseudoplastic), $n<1$.

Shear thickening (dilatant), $n>1$.

The general form for the above models is

$\tau=\beta+k\left(\frac{\mathrm{d} u}{\mathrm{~d} y}\right)^{n}$,

where $k$ is the consistency coefficient, $n$ is the power law index, $\beta$ is the yield stress.

The rheological characteristics of crude oil have a very important role in the drilling, production and transportation through pipeline. The crude oil behavior may change from Newtonian behavior at which rheological properties are simple to non-Newtonian behavior depending on the variation of the wax content and viscosity. The influence of asphaltenes in the Venezuelan crude oil were investigated by Pierre et al. (2004). They found that at low temperature, the viscosity was dropped under shear stress and the crude oil behaved as a shear thinning model, but at high temperature, asphaltenes behaved like Newtonian fluid. It was suggested that the rheological behavior of emulsion of Algerian crude oil-water follows Bingham model (Benziane and Zahloul 2013). Similar rheological work has been conducted by Abd et al. (2014) on stabilized Malaysian crude oil and water emulsion by cocamide at different water fractions. Their results showed that at higher cocamide concentration and lower water fraction have the most effective conditions in stabilizing the emulsion, and the tested samples were modeled by shear thinning formula.

\section{Methodology}

Two types of crude oils from Sultanate of Oman were used in preset investigation, light crude from Yibal oil field; density $0.818 \mathrm{~g} / \mathrm{cc}$ and API gravity $41.3 @ 15.56{ }^{\circ} \mathrm{C}$ and heavy crude from Mukhaizna oil field; density $0.95 \mathrm{~g} / \mathrm{cc}$ and API gravity $17 @ 15.56{ }^{\circ} \mathrm{C}$.

In this study, to our knowledge the application of bio materials as a potential viscosity reduction agent for crude oil were reported first time. Four types of materials were used: palm tree fiber, walnut shell and kernel of dates (roasted and unroasted). Each material was washed thoroughly with water, dried using hot air oven at $60{ }^{\circ} \mathrm{C}$, and then grounded. The grounded bio material was sieved to obtain powder with two different particle sizes; 75 and
$150 \mu \mathrm{m}$. Each bio material was used in amount of 10,20 and $100 \mathrm{ppm}$ crude oil. These bio materials and crude oil were thoroughly mixed using digital magnetic stirrer. Each material was soaked in crude oil for $24 \mathrm{~h}$ before the experiment. The work was conducted at a temperature of $22^{\circ} \mathrm{C}$.

\section{Flowability test}

Piping rack was manufactured for testing the flowability time of crude oil with and without bio materials. Photo of piping rack is shown in Fig. 1. This rack consists of three galvanized pipes, each $2 \mathrm{~m}$ long and $0.5 \mathrm{in}$. diameter. The piping rack was set with a slope of angle $2^{\circ}$. The experimental work was carried out at atmospheric pressure.

\section{Rheological test}

Rheological measurements for samples of crude oil with and without suspended fiber were carried out using TA-Rheometer. Peltier Plate geometry was selected. The most commonly procedure used is the flow ramp for the non-Newtonian fluid. The procedure started by selecting the type geometry by choosing the DIN Peltier Plate and set the system for the zero gap. Then each sample was loaded onto the geometry. The test conditions in this work were: sample interval is 10

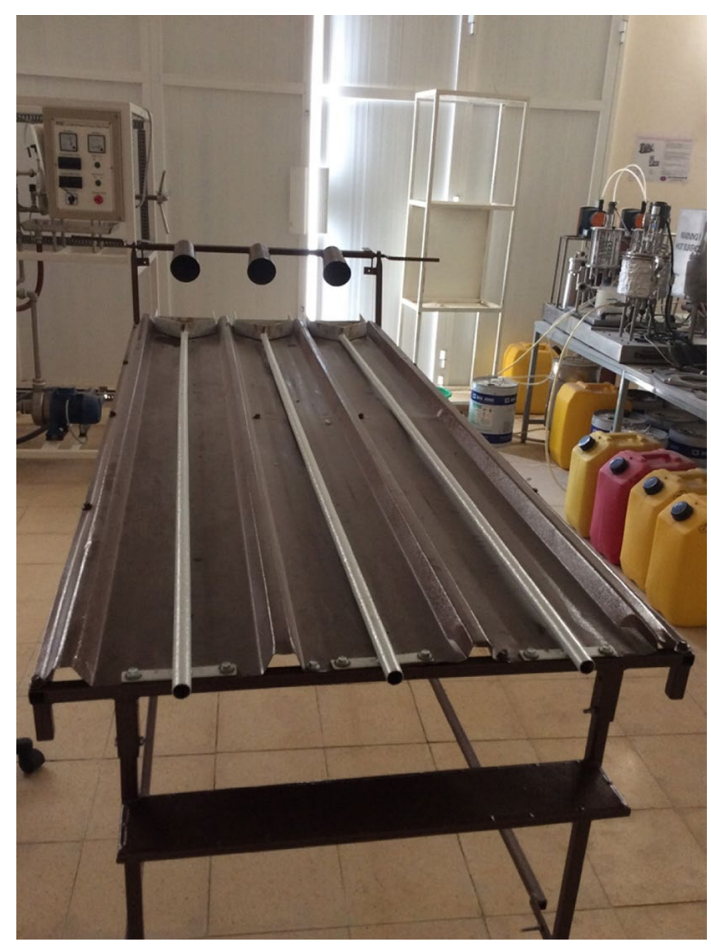

Fig. 1 Photo of piping rack 


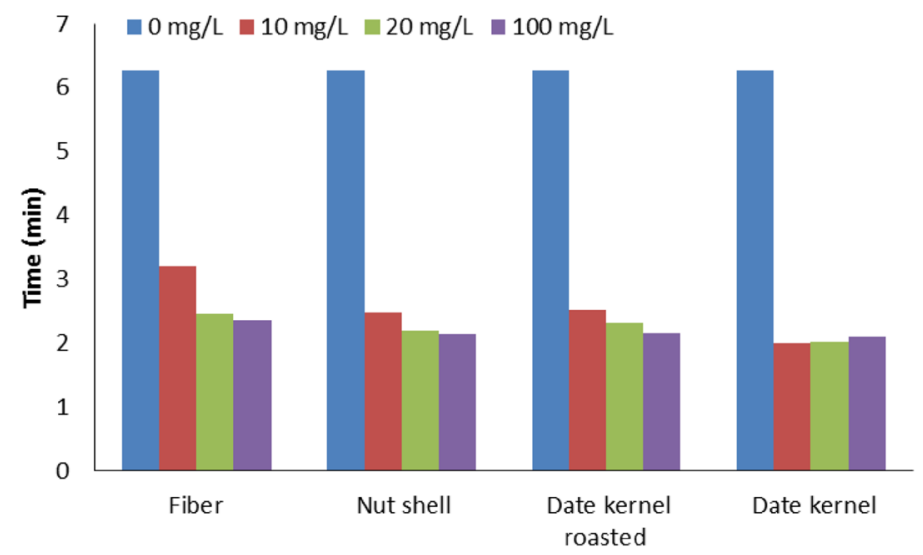

(a) $75 \mu \mathrm{m}$

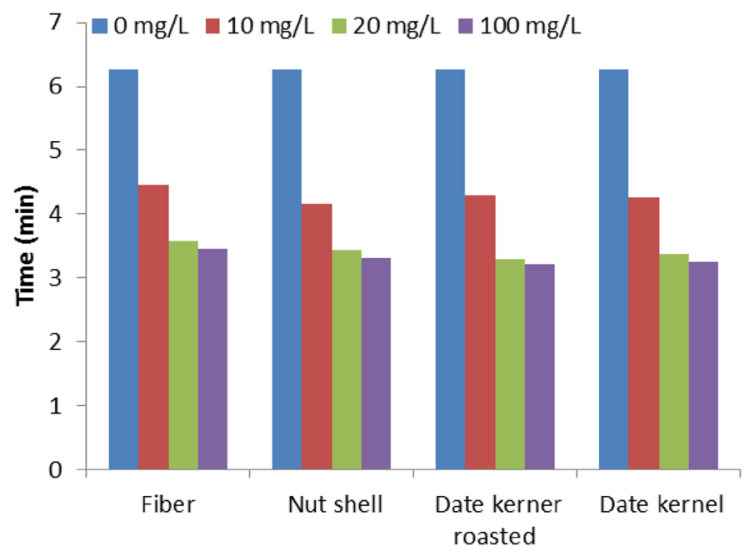

(b) $150 \mu \mathrm{m}$

Fig. 2 Flowing time of light crude oil using bio materials

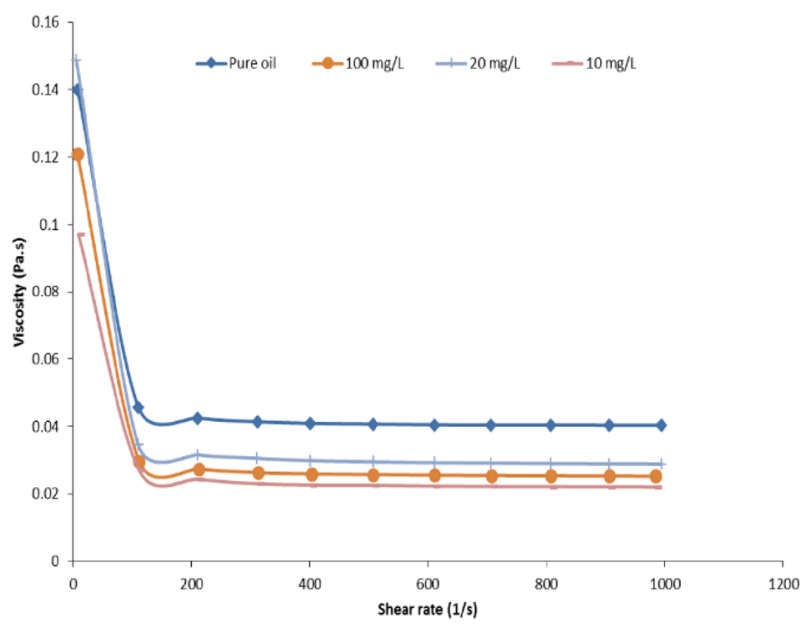

(a) Fiber

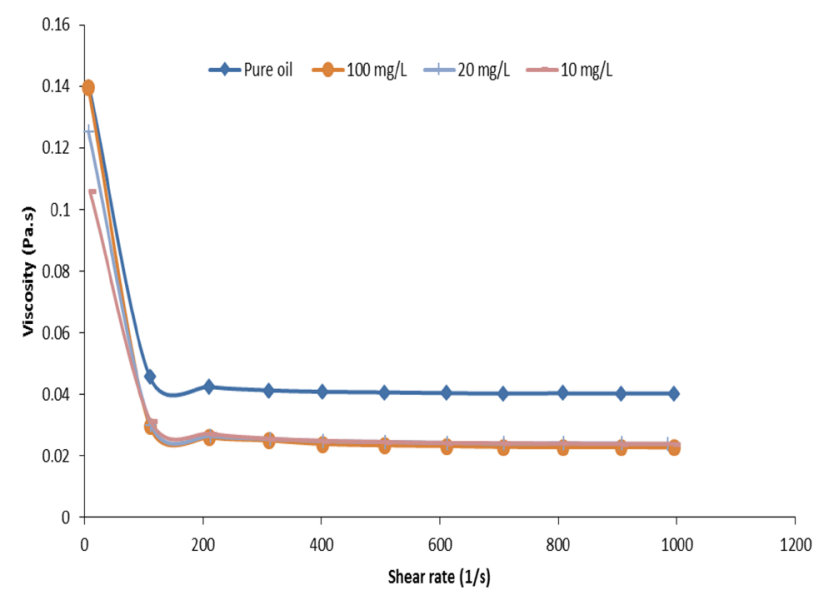

(c) Kernel of Date -roasted

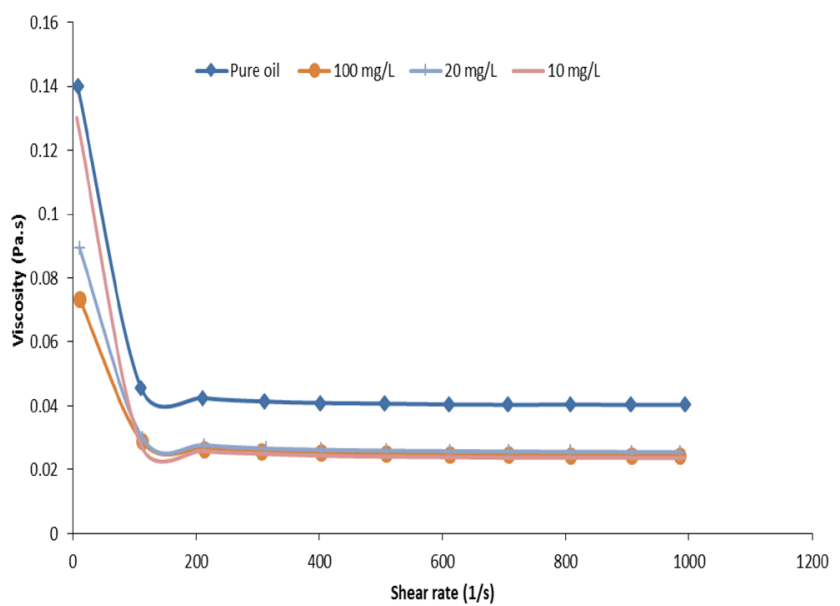

(b) Nut shell

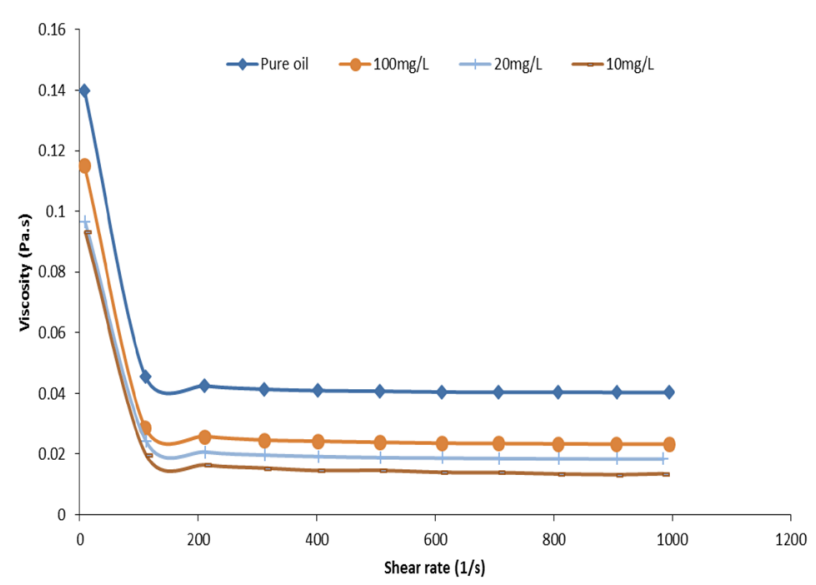

(d) Kernel of Date

Fig. 3 Viscosity of light crude oil using bio materials $(75 \mu \mathrm{m})$ 
point per decades, shear rate range of $0-1000 \mathrm{~s}^{-1}$ and sample temperature $25{ }^{\circ} \mathrm{C}$.

\section{Results and discussion}

The selected bio waste materials were separately mixed with two types of Oman's crude oils and used as viscosity reduction. These materials were prepared at two different particle sizes; 75 and $150 \mu \mathrm{m}$ at different concentrations; 10, 20, $100 \mathrm{ppm}$.

\section{Light crude oil}

The effects of using bio materials as viscosity reduction on the flowing time of the light crude oil are shown in Fig. 2. It

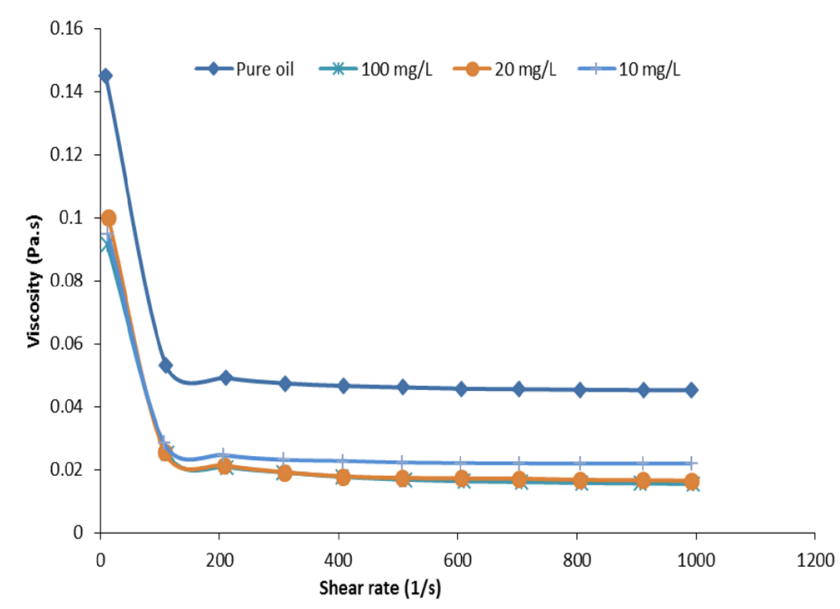

(a) Fiber

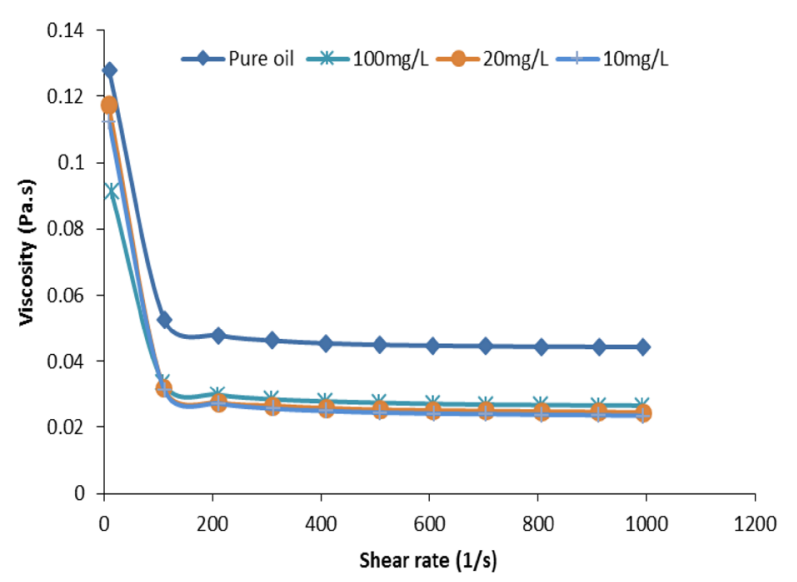

(c) Kernel of Date -roasted can be seen that the flow time of light crude oil was reduced by $42 \%$ when using particle size $75 \mu \mathrm{m}$ compared to that of pure crude oil, and reduced by $66 \%$ when using particle size $150 \mu \mathrm{m}$ due to larger oil-solid particles. These results indicate that the using of bio materials would be attributed to the stabilization of the turbulent boundary layer.

The rheological properties, such as viscosity, yield stress and shear stress of the crude oil using bio materials were studied. The viscosity results are shown in Figs. 3 and 4 using 75 and $150 \mu \mathrm{m}$ particle size respectively. In whole, and regardless the use of bio materials, it was observed rapid decreases in the apparent viscosities as shear rate increased up to $1000 \mathrm{~s}^{-1}$ and reaching limiting viscosities. The limiting viscosity is considered to be one of the rheological characterization terms. The results of limiting viscosities for different types of bio materials, particle sizes and concentrations are shown in Fig. 5. As observed, a $62 \%$ decrease in the

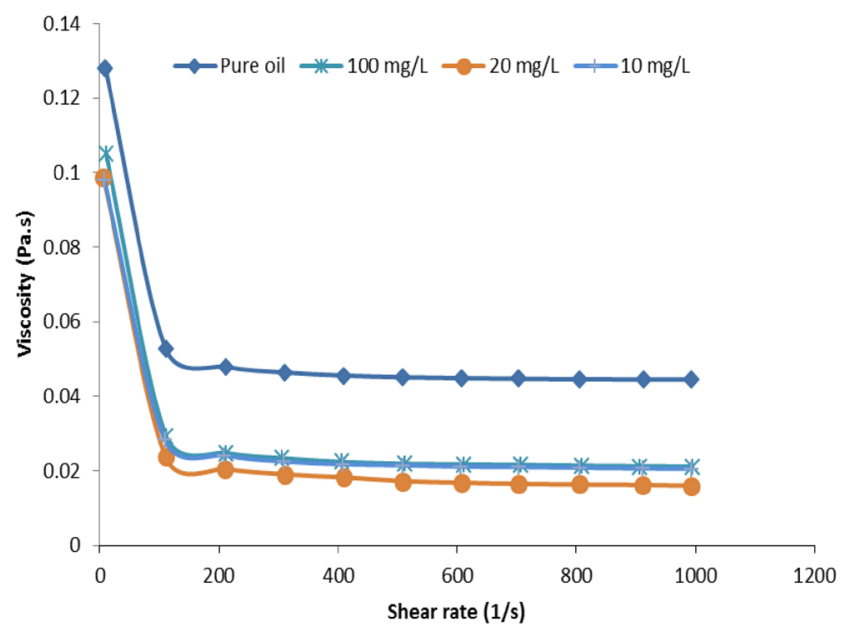

(b) Nut shell

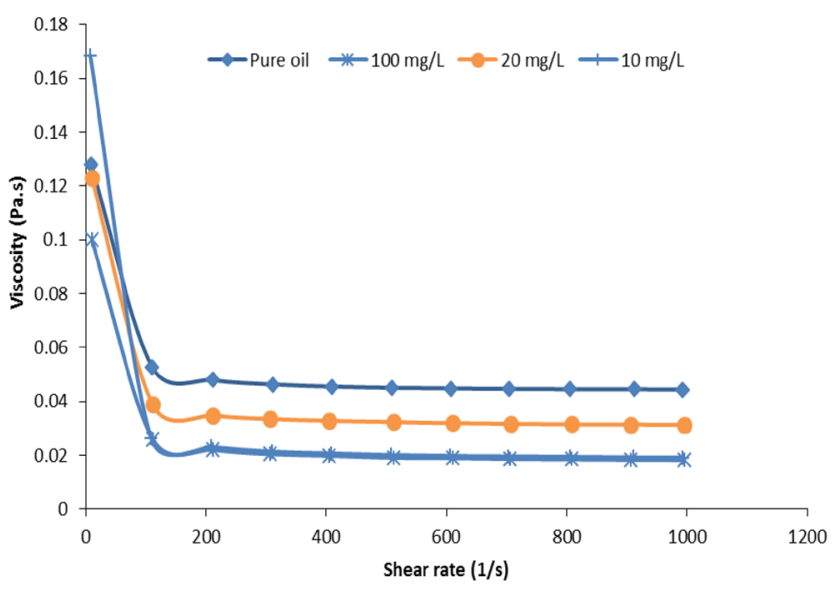

(d) Kernel of Date

Fig. 4 Viscosity of light crude oil using bio materials $(150 \mu \mathrm{m})$ 


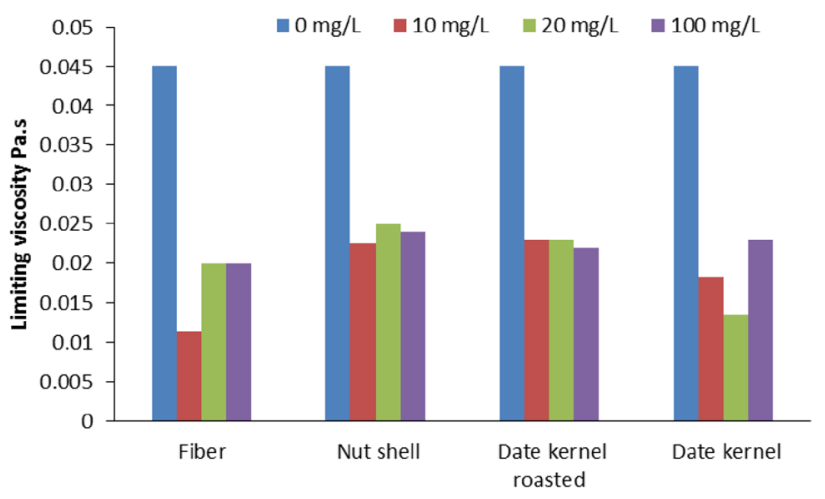

(a) $75 \mu \mathrm{m}$

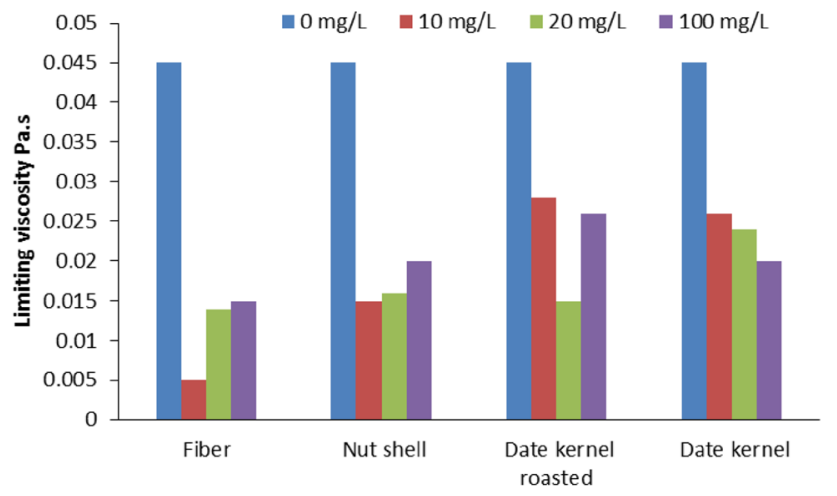

(b) $150 \mu \mathrm{m}$

Fig. 5 Limiting viscosity of light crude oil using bio materials

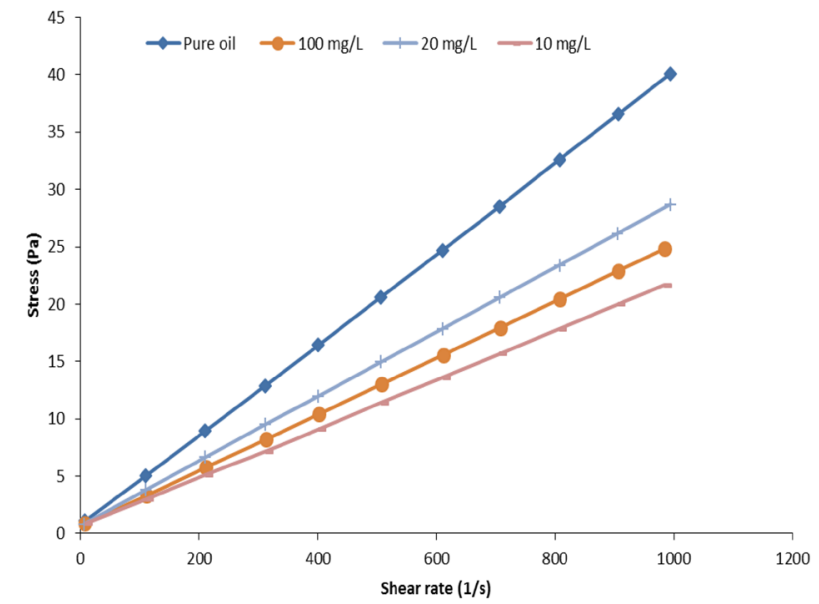

(a) Fiber

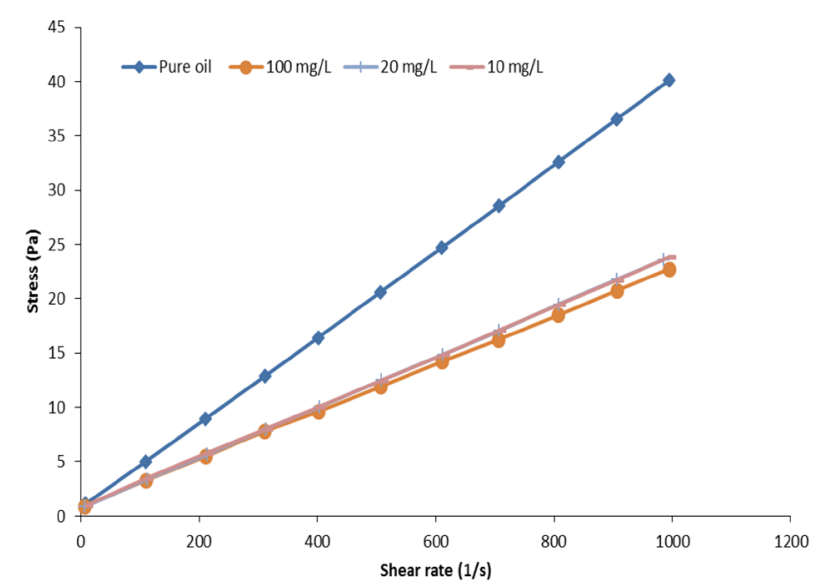

(c) Kernel of Date -roasted

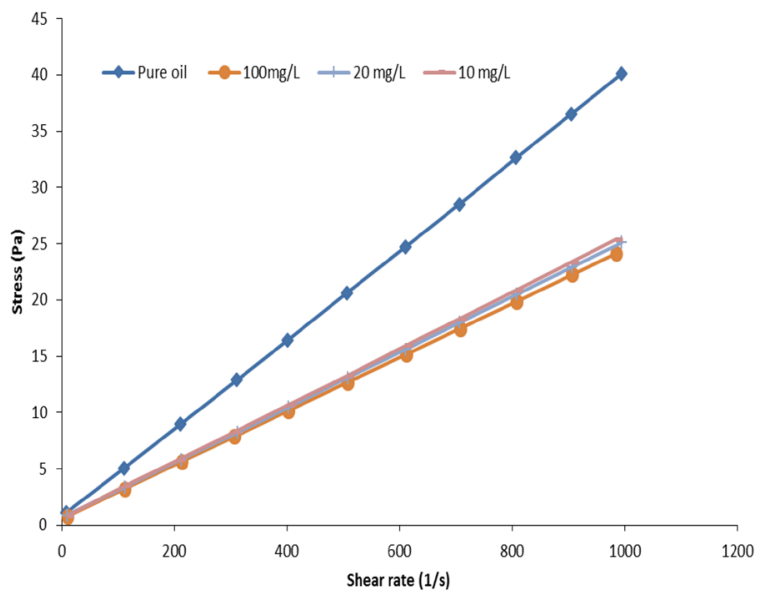

(b) Nut shell

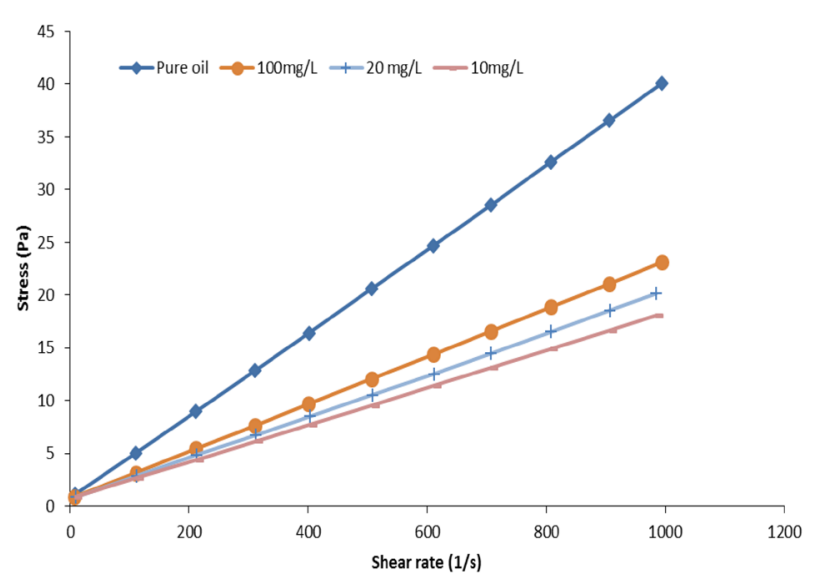

(d) Kernel of Date

Fig. 6 Shear rate of light crude oil using bio materials $(75 \mu \mathrm{m})$ 
limiting viscosity was achieved using particle size $75 \mu \mathrm{m}$ and $75 \%$ using particle size $150 \mu \mathrm{m}$. The lowest limiting viscosity was achieved when using fiber of date palm. These additives showed no much effect on oil initial viscosity which indicates no changes in crude oil physical properties.

Ramp shear stress test was performed to analyze the rheological behavior of the crude oil samples with and without using bio materials. The obtained results using particle sizes 75 and $150 \mu \mathrm{m}$ are shown in Figs. 6 and 7, respectively. As shown, all samples of pure oil under stress followed Bingham model, values of consistency index ' $k$ ' were calculated and shown in Fig. 8. The results showed that ' $k$ ' value for pure oil equal to 0.04 whereas the average ' $k$ ' value of oil mixed with bio material equal to 0.024 . The value of consistency index ' $k$ ' refers to the viscosity and stress at a specified shear rate. The achieved low ' $k$ ' values indicate the lower viscosities and lower stress of the oil samples using bio materials. This behavior would be considered best for pumping and transportation.

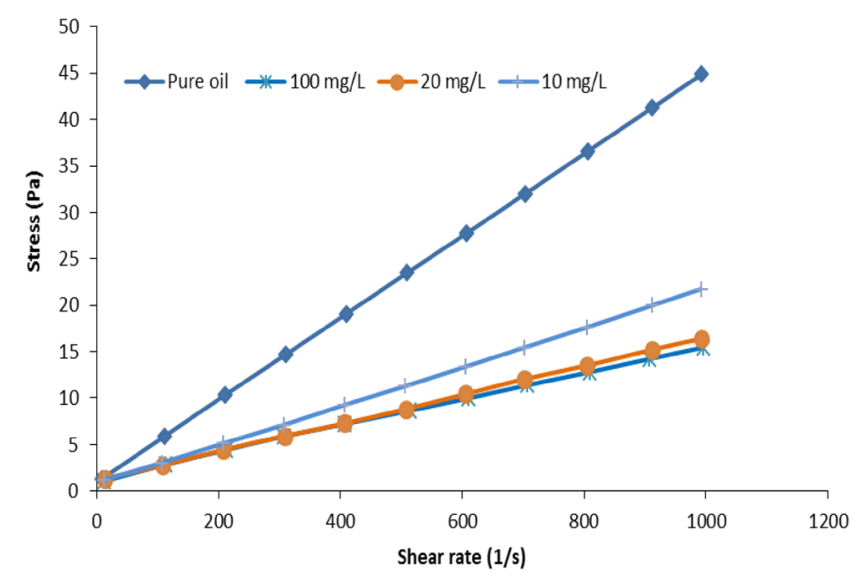

(a) Fiber

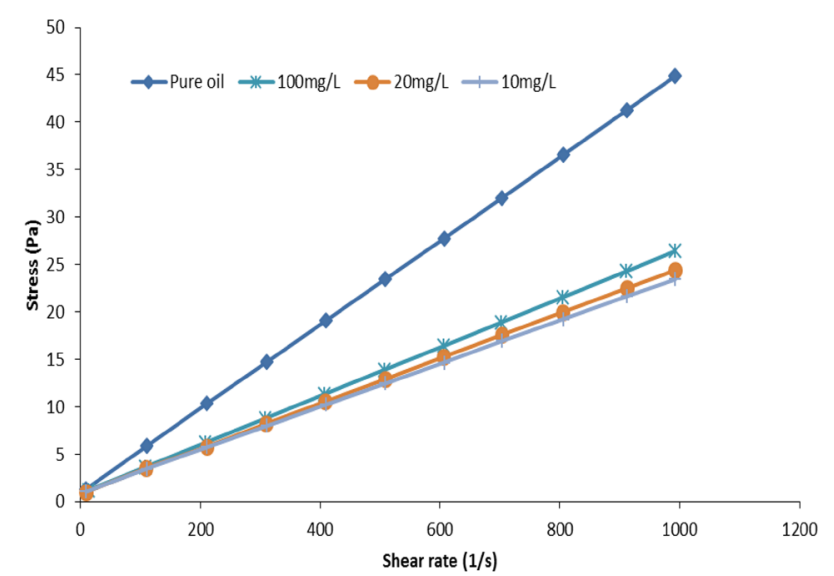

(c) Kernel of Date -roasted
Likewise, yield stress can be defined as the limiting stress below which the material sample under test behaves like solid. From the rheological tests, as shown in Fig. 9, it was observed that the addition of bio materials results in lower yield shear stresses due to reduction of oil viscosity.

These results give a good indication on the effectiveness of using bio materials on improving flow in pipeline which could benefit to reduce the pumping energy.

\section{Heavy crude oil}

The effects of using bio materials as viscosity reduction on the flowing time of the heavy crude oil are shown in Fig. 10. It can be seen that the flow time of heavy crude oil was reduced by $50 \%$ when using particle size $75 \mu \mathrm{m}$ compared to that of pure crude oil, and reduced by $65 \%$ when using particle size $150 \mu \mathrm{m}$ due to larger oil-solid particles. These results indicate that the using of bio materials would be attributed to the stabilization of the turbulent boundary layer.

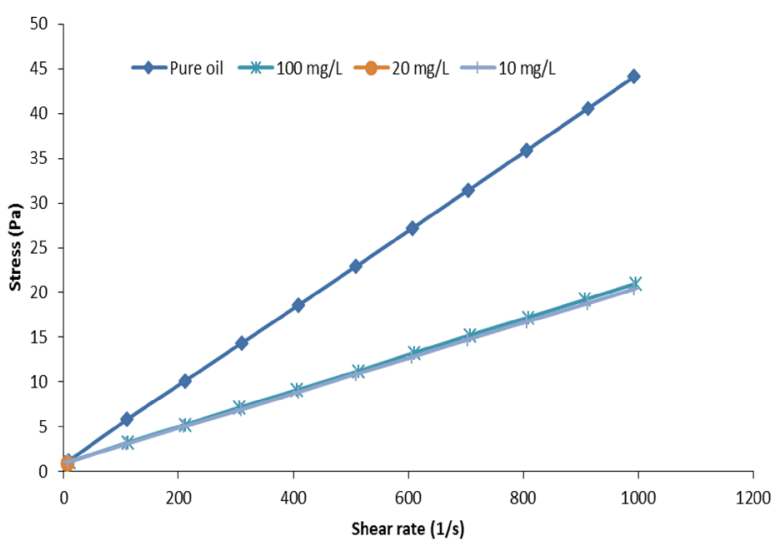

(b) Nut shell

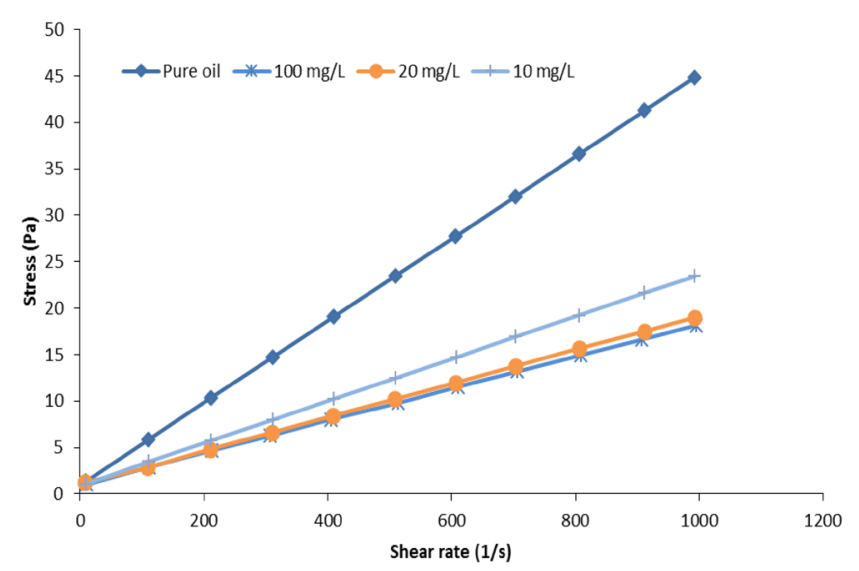

(d) Kernel of Date

Fig. 7 Shear rate of light crude oil using bio materials $(150 \mu \mathrm{m})$

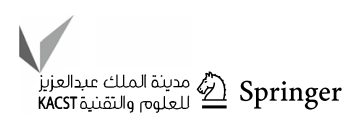




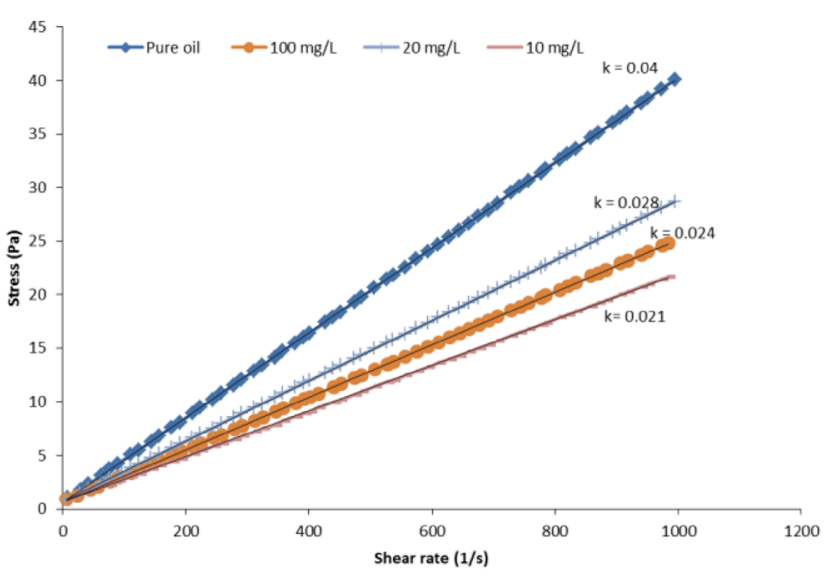

(a) $75 \mu \mathrm{m}$

Fig. 8 Consistency index 'k' of light crude oil using bio materials

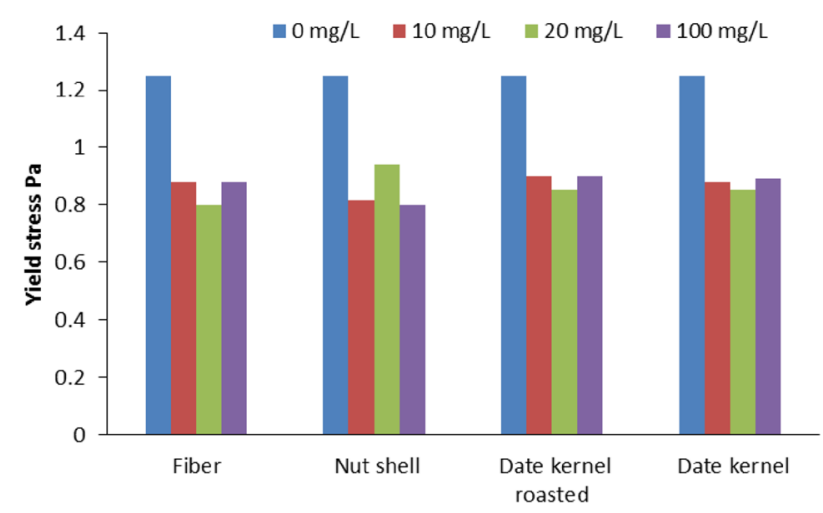

(a) $75 \mu \mathrm{m}$

Fig. 9 Yield stress of light crude oil using bio materials

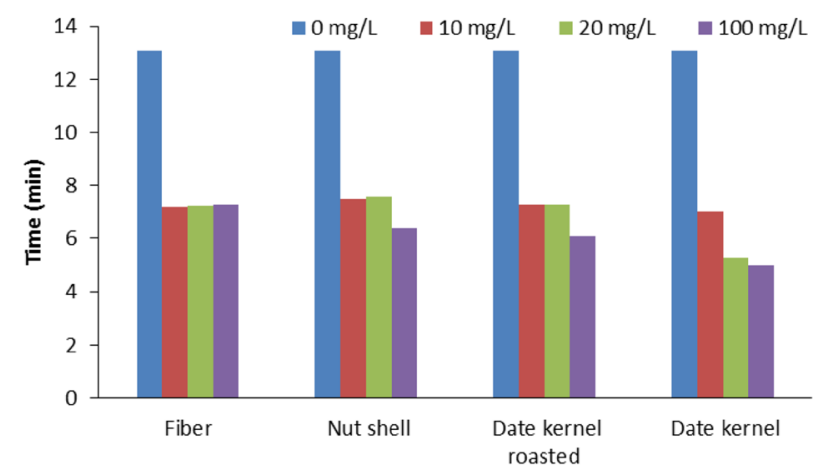

(a) $75 \mu \mathrm{m}$

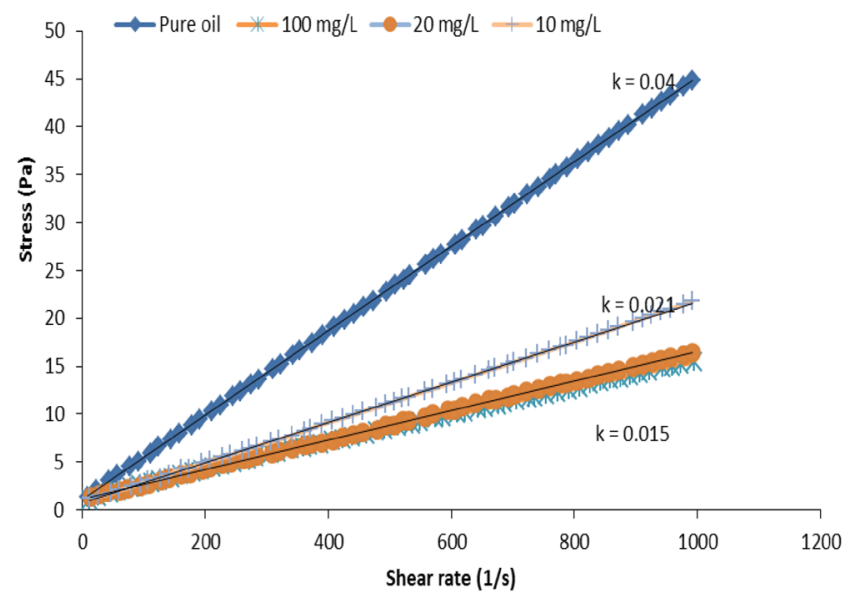

(b) $150 \mu \mathrm{m}$

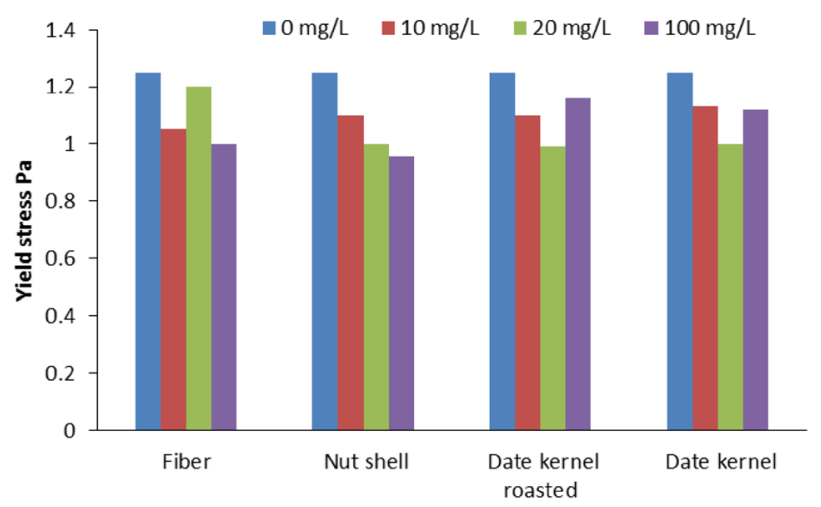

(b) $150 \mu \mathrm{m}$

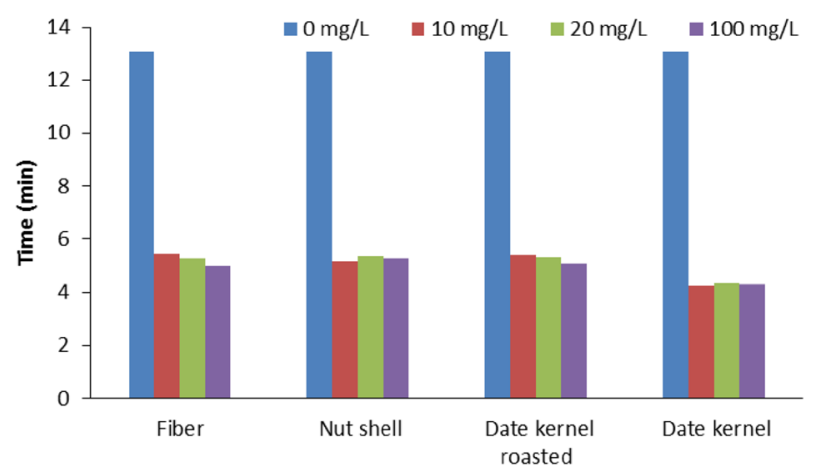

(b) $150 \mu \mathrm{m}$

Fig. 10 Flowing time of heavy crude oil using bio materials 


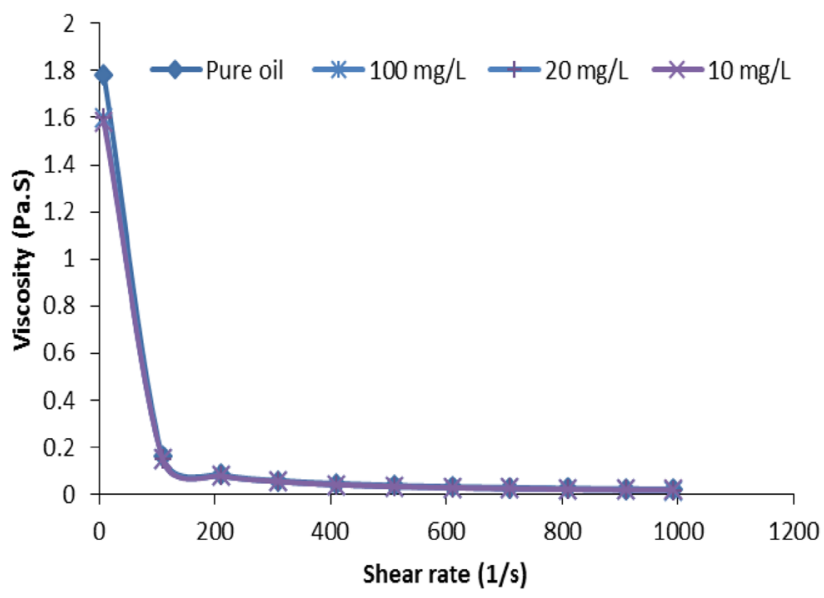

(a) Fiber

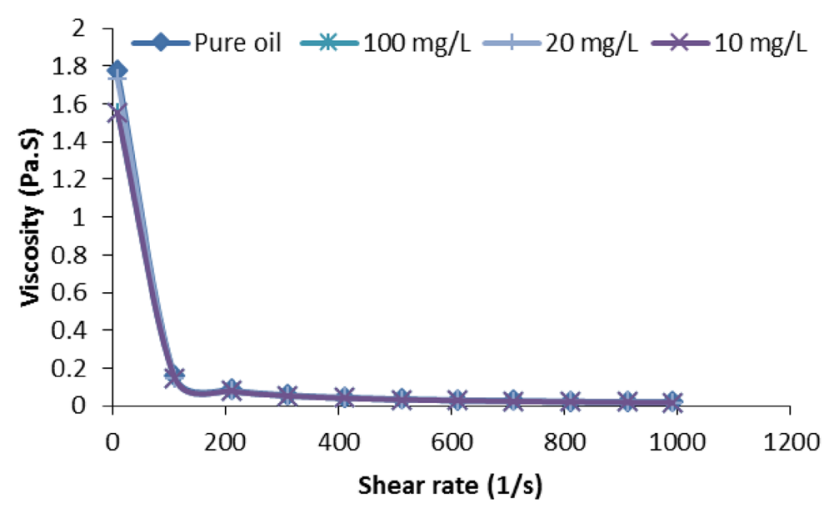

(c) Kernel of Date -roasted

Fig. 11 Viscosity of heavy crude oil using bio materials $(150 \mu \mathrm{m})$

It is worth mentioning that applying $150 \mu \mathrm{m}$ size bio materials has induced a good impact on reducing oil viscosity and yield stress. Viscosity and shear stress tests were carried out on the heavier Oman's crude oil with and without using bio materials of particle size of $150 \mu \mathrm{m}$ is shown in Figs. 11, 12 and 13. The results of the oil apparent viscosities are shown in Fig. 11. The results showed rapid decreasing in all apparent viscosities as the rate of shear strain was increased and then reaching constant limiting viscosities at the higher shear rate of $1000 \mathrm{~s}^{-1}$. The results of limiting viscosities for different concentrations are shown in Fig. 12. It can be observed that the limiting viscosity decreased using bio materials compared to that of pure crude oil for all samples. In addition, the obtained results showed no substantial effect on oil initial viscosity which indicates no change in heavy crude oil physical properties.

Ramp shear stress test was performed and the results are presented in Fig. 13. Pure heavy crude oil followed shear thinning (pseudoplastic) model with $n=0.0506$ as shown in Fig. 14, whereas, all samples of crude oil mixed with

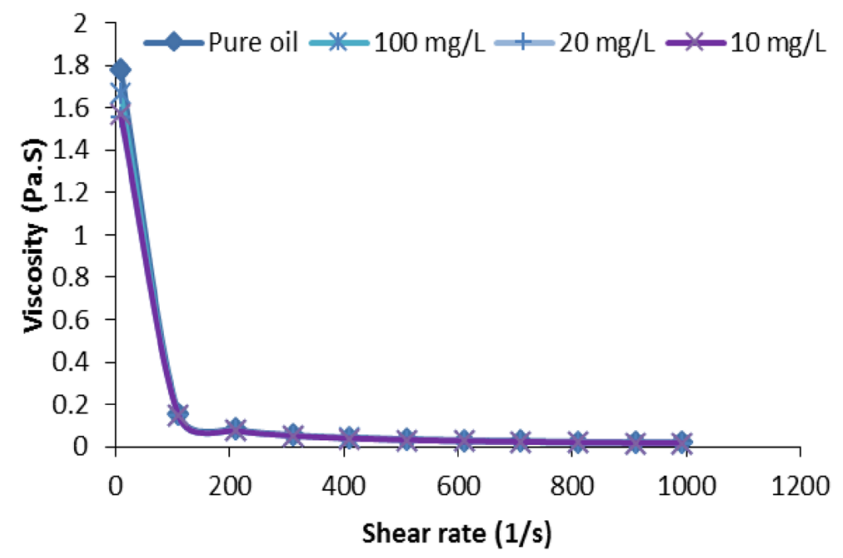

(b) Nut shell

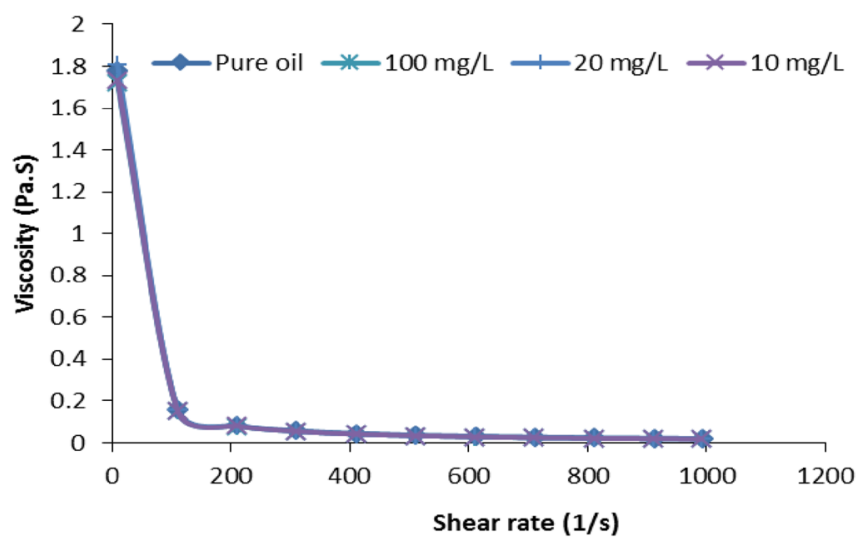

(d) Kernel of Date

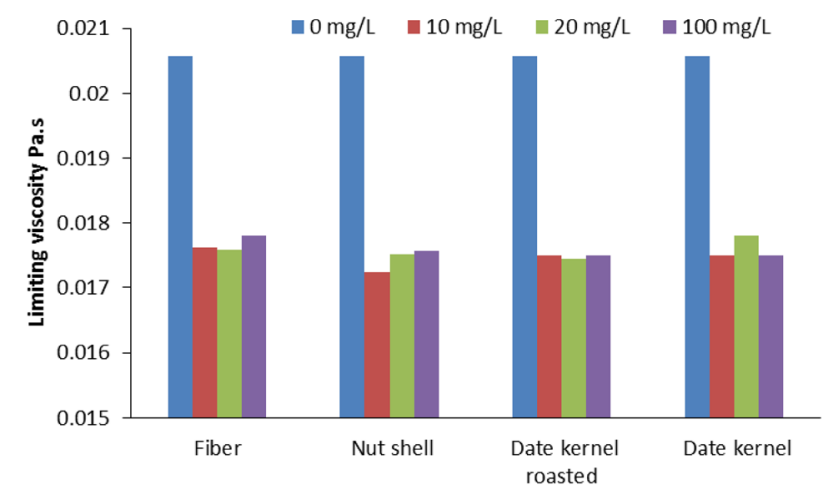

Fig. 12 Limiting viscosity of heavy crude oil with $150 \mu \mathrm{m}$ bio materials

bio materials followed Bingham model with ' $k$ ' value of average 0.0014 (Fig. 14). The achieved low values of ' $k$ ' indicate the lower viscosities and stress of the heavy crude 


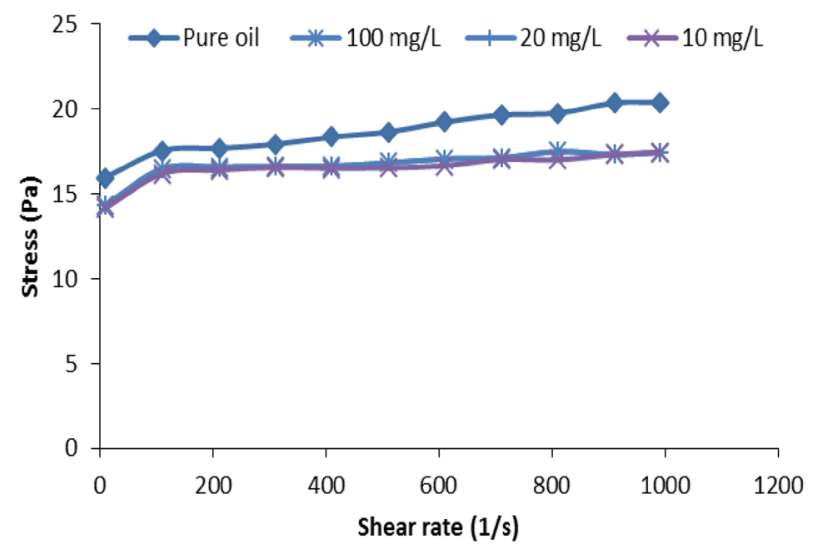

(a) Fiber

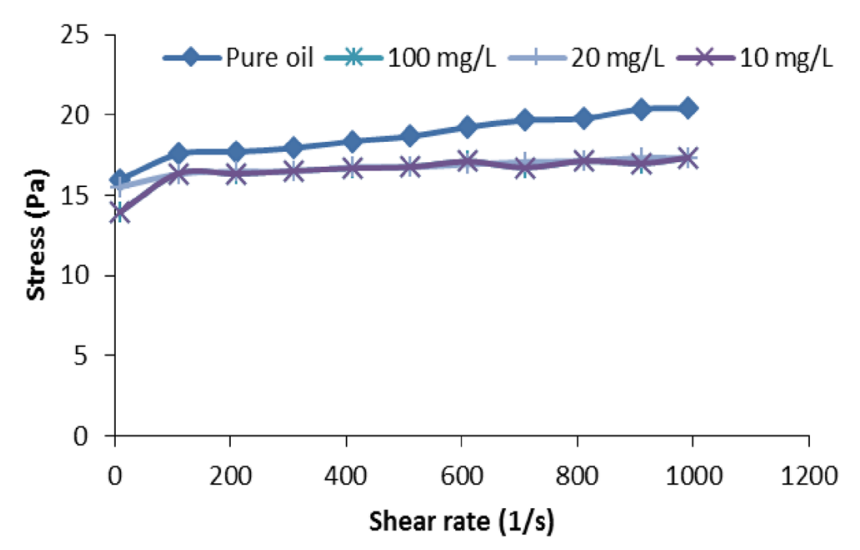

(c) Kernel of Date -roasted

Fig. 13 Shear rate of heavy crude oil using bio materials $(150 \mu \mathrm{m})$

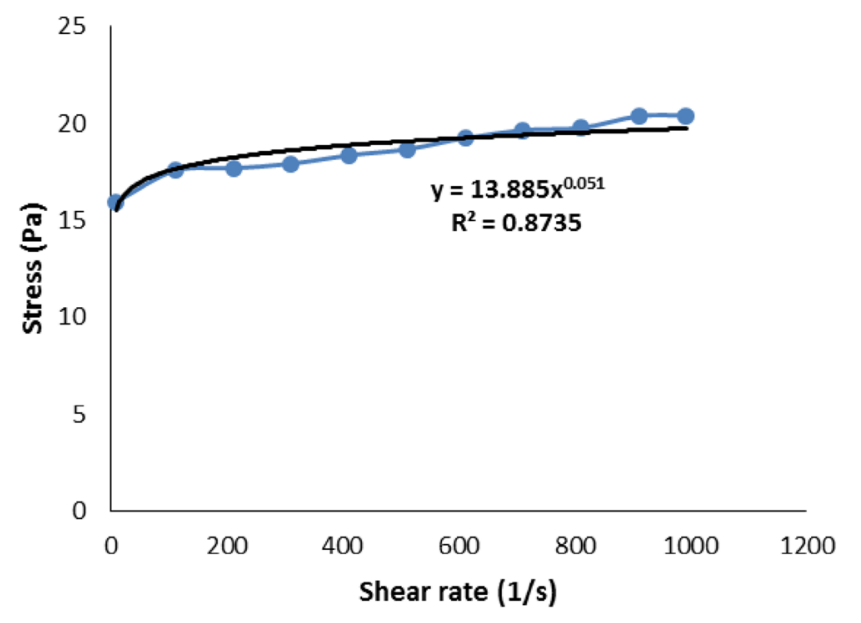

(a) Shear thinning model

Fig. 14 power function for shear thinning for heavy crude oil

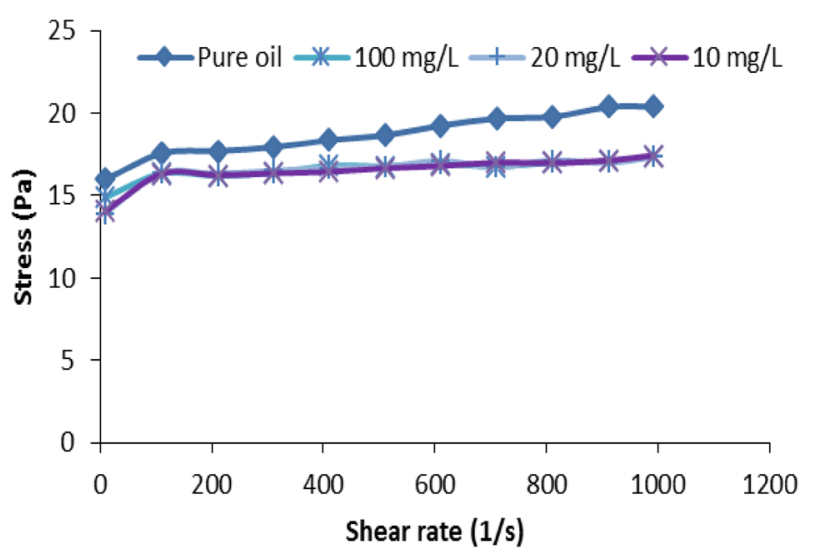

(b) Nut shell

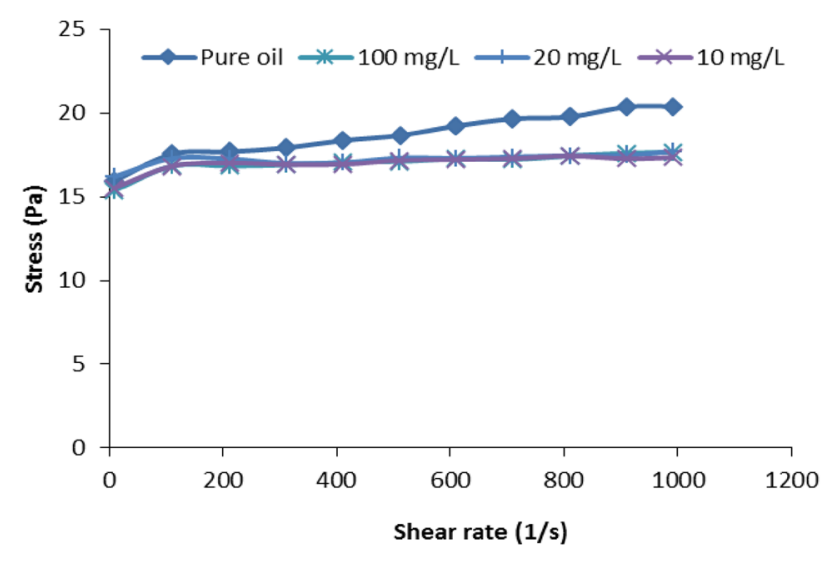

(d) Kernel of Date

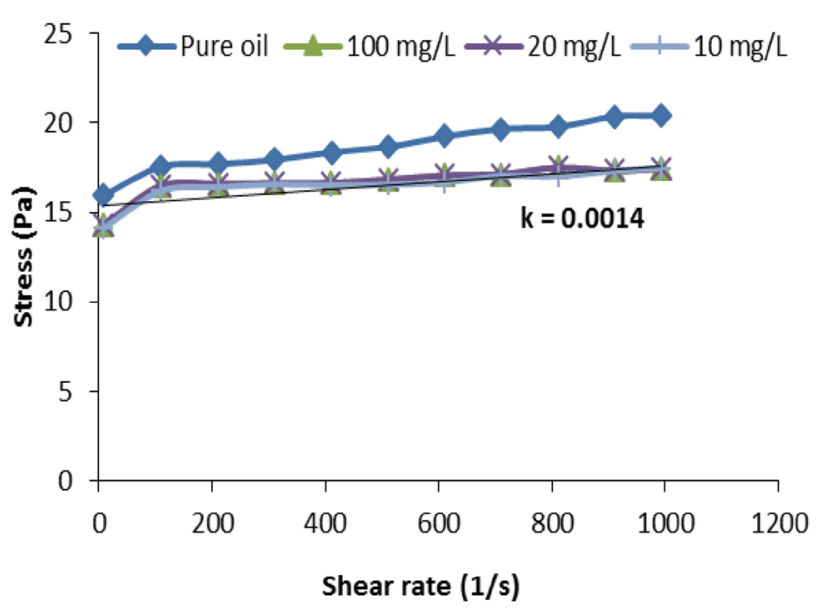

(b) Consistency index ' $\mathrm{k}$ ' 
oil when using bio materials, thus, these materials would be considered an alternative option for viscosity reduction.

Likewise, yield stress results showed that the addition of bio materials lower yield shear stresses for all bio material except for sample with fiber material due to the reduction of drag viscosities as shown in Fig. 15.

These results give a good indication on the effectiveness of using bio materials on improving flow in pipeline and could result in reducing the pumping energy.

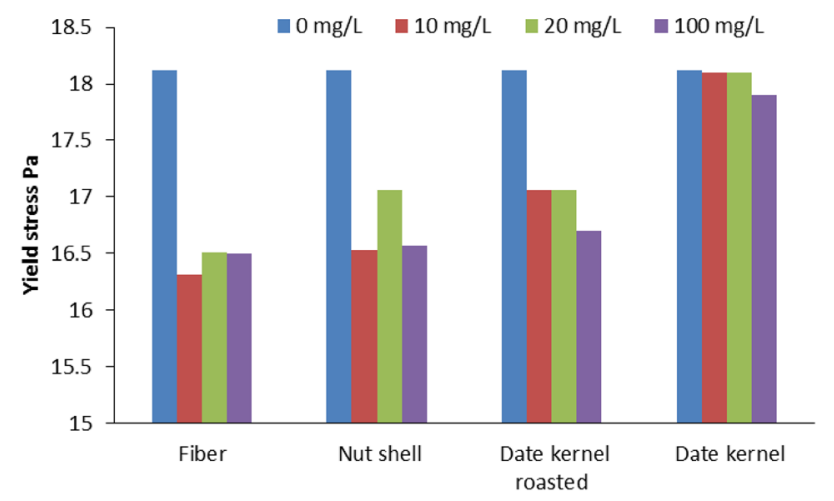

Fig. 15 Yield stress of heavy crude oil with $150 \mu \mathrm{m}$ bio materials

Table 1 Summary of results

\begin{tabular}{|c|c|c|c|c|}
\hline & Fiber & Nut shell & $\begin{array}{l}\text { Date } \\
\text { kernel } \\
\text { roasted }\end{array}$ & Date kernel \\
\hline \multicolumn{5}{|c|}{ Light crude oil with particle size $75 \mu \mathrm{m}$} \\
\hline $\begin{array}{l}\% \text { limiting viscosity } \\
\text { reduction }\end{array}$ & 61.93 & 47.04 & 49.63 & 59.41 \\
\hline$\%$ yield stress & 31.73 & 31.89 & 29.33 & 30.13 \\
\hline \multicolumn{5}{|c|}{ Light crude oil with particle size $150 \mu \mathrm{m}$} \\
\hline $\begin{array}{l}\% \text { limiting viscosity } \\
\text { reduction }\end{array}$ & 74.82 & 62.22 & 48.89 & 48.15 \\
\hline$\%$ yield stress & 13.33 & 18.53 & 13.33 & 13.33 \\
\hline \multicolumn{5}{|c|}{ Heavy crude oil with particle size $150 \mu \mathrm{m}$} \\
\hline $\begin{array}{l}\% \text { limiting viscosity } \\
\text { reduction }\end{array}$ & 14.1 & 15.22 & 15.04 & 14.44 \\
\hline$\%$ yield stress & 9.3 & 7.73 & 6.51 & 0.478 \\
\hline
\end{tabular}

In the case of heavy crude oil, it can be seen small peaks in the responses of yield stresses, this may be due to the strong bonds between oil-oil and oil-materials particles causing stress overshoot. When reaching shear rate of $150 \mathrm{~s}^{-1}$, bonds were broken and shear stress decreased and, all samples behaved like samples without strong bonds and showed the same trend.

The examined bio materials of various chemical compositions, structures and adherence to oil have resulted in different reflection on the measured limiting viscosities and yield stresses.

The summary of results is presented in Table 1 . The use of bio materials reduced both the limiting viscosities and yield stress, the light crude oils was reduced by average $62 \%$ using particle size $75 \mu \mathrm{m}$ and $75 \%$ using particle size $150 \mu \mathrm{m}$. However, limiting viscosity of heavy crude oil was reduced by $14 \%$. In respect to yield stress, it was observed that the addition of bio materials resulted lower yield stress, light crude reduced by average $32 \%$ while heavy crude oil reduced by $9.3 \%$.

The SEM images $1000 \times$ magnification taken for pure bio materials and that immersed crude oil for $24 \mathrm{~h}$ is shown in Fig. 16. These images show reduction in surface roughness of particles immersed in oil compared to pure particles. This may lead to the possibility of smoothing mechanism and reduction in friction of drag viscosities and hence improving crude oil transportation in pipeline.

\section{Conclusions}

The large availability amount of waste bio material from palm trees is 2 million tonnes annually in GCC, it is more than sufficient to be economically utilized to decrease viscosity of crude oil. The bio materials were found to be effective drag reducing agent when used with Oman's crude oil. The limiting viscosities were decreased by more than $50 \%$ while yield stresses were reduced by more than $30 \%$. Among four of the used material, the better result achieved using fiber of palm tree, and the most effective particle size was $150 \mu \mathrm{m}$. The lowest oil viscosity was obtained using concentration of $20 \mathrm{mg} \mathrm{L}^{-1}$. In respect to yield stress results, it was observed that the addition of bio materials produced lower yield shear stresses for all types of bio material used. Rheological results showed that the light crude oil follows Bingham model whereas heavy crude oil follows shear thinning model. The microscopic study on bio materials proved the reduction in surface roughness of particles immersed in oil compared to dry particles. The reduction in surface roughness led to reduction in drag viscosity. 


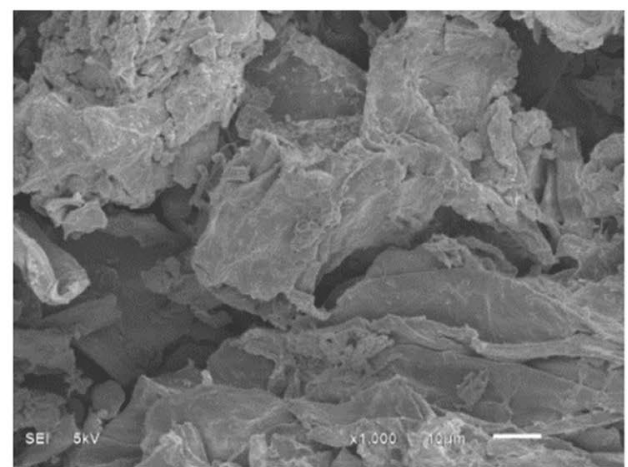

(a) Fiber

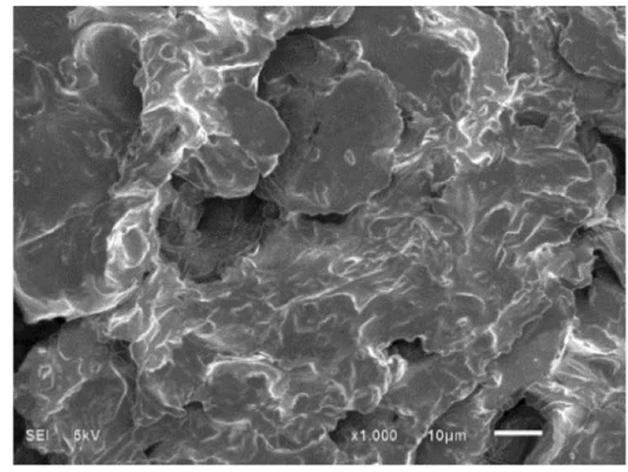

(c) Nut Shell

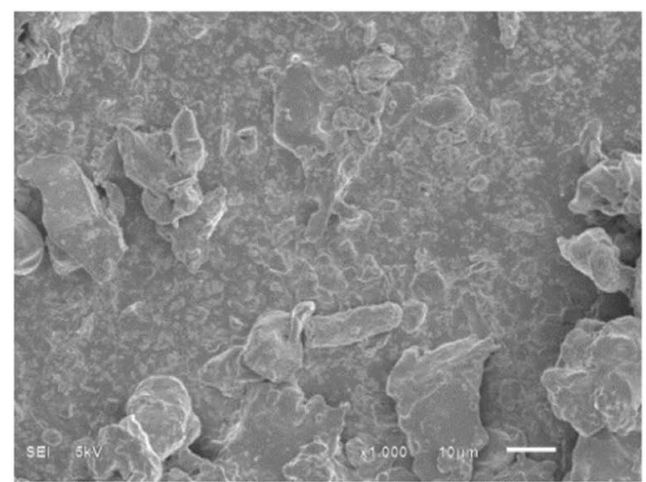

(e) Kernel of dates (roasted)

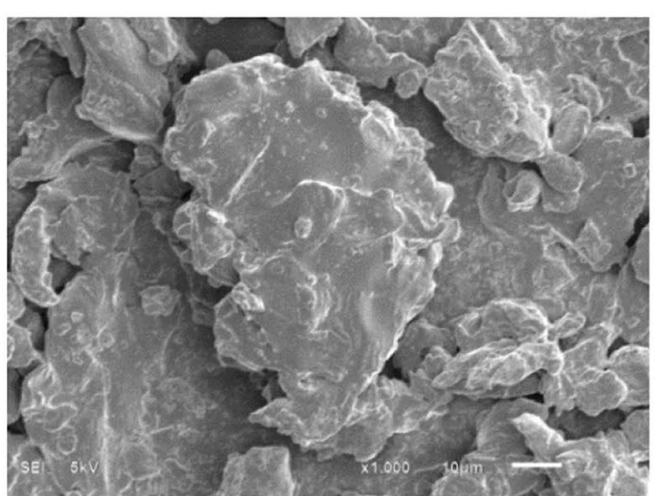

(g) Kernel of dates

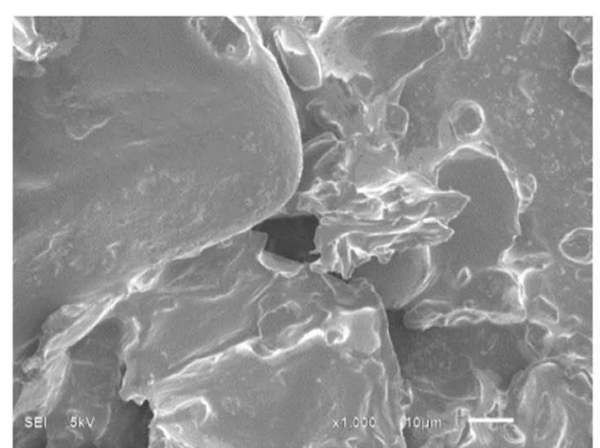

(b) Fiber with oil

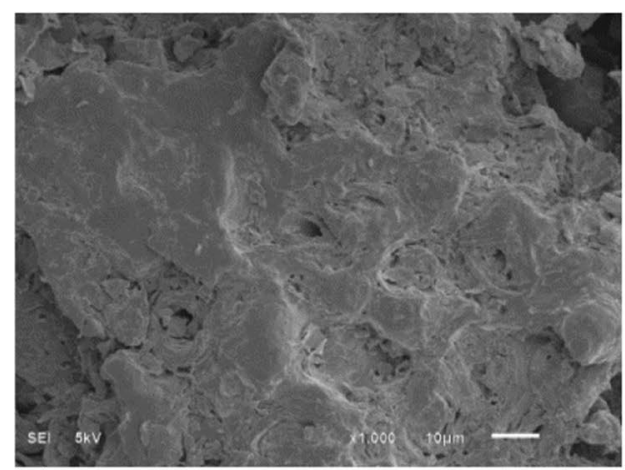

(d) Nut Shell with oil

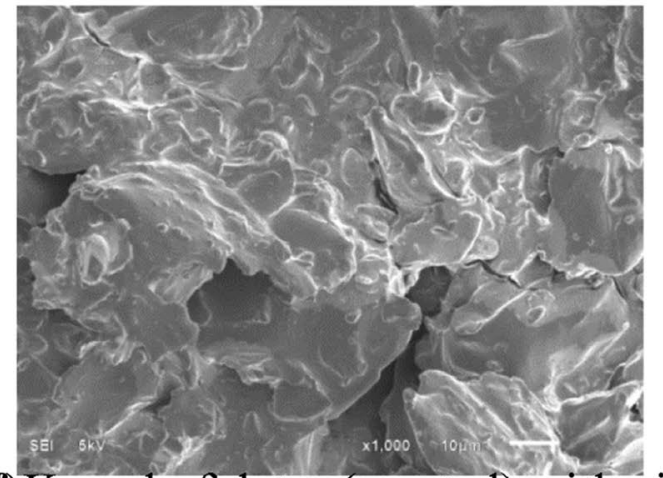

(f) Kernel of dates (roasted) with oil.

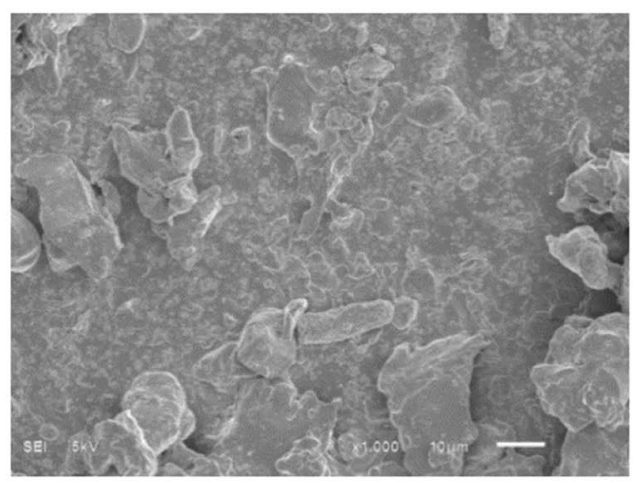

(h) Kernel of dates with oil.

Fig. 16 SEM images $\times 1000$ magnification of bio materials with and without oil 
Open Access This article is distributed under the terms of the Creative Commons Attribution 4.0 International License (http://creativeco mmons.org/licenses/by/4.0/), which permits unrestricted use, distribution, and reproduction in any medium, provided you give appropriate credit to the original author(s) and the source, provide a link to the Creative Commons license, and indicate if changes were made.

\section{References}

Abd RM, Nour AH, Sulaiman AZ (2014) Kinetic stability and rheology of water-in-crude oil emulsion stabilized by cocamide at different water volume fractions. Int J Chem Eng Appl 5(2):204-209

Akindoyo EO, Abdulbari HA (2015) Drag reduction efficacy of CTABr and nanosilica particles using rotating disk apparatus (RDA). Aust J Basic Appl Sci 9(8):136-144

Al Beshara JM, Salman OA, Akashah SA (1987) Viscosity of crude oil blends. Ind Eng Chem Res 26:2445-2449

Al Zahrani SM (1997) A generalized rheological model for shear thinning fluid. J Petrol Sci Eng 17:211-215

Ashrafizadeh SN and. Kamran M (2012) Emulsification of heavy crude oil in water for pipeline transportation. J Petrol Sci Eng 71:205-211

Benslimane A, Bekkour K, Francois P (2013) Effect of addition of Carboxymethylcellulose (CMC) on the rheology and flow properties of bentonite suspensions. Appl Rheol 23(1):13475

Benslimane K, Bekkour P, Francois H, Bechir (2016) Laminar and turbulent pipe flow of bentonite suspensions. J Pet Sci Eng 139:85-93

Benziane MM, Zahloul H (2013) rheological behaviors of crude oil in the presence of water. Int $\mathrm{J}$ Mech Aerosp Ind Mechatron Manuf Eng 7(3):521-525

Calin A (2009) The influence of drag-reducing additives on crude oil emulsions in pipeline flow. UPB Sci Bull C 71(3):197-2014

Chemloul NS (2014) Experimental study of the drag reduction in turbulent pipe flow. Energy 64:818-827

Drappier J, Divoux T, Amarouchene Y, Bertrand F, Rodts S, Cadot O et al (2006) Turbulent drag reduction by surfactants. Europhys Lett 74(2):362-368

El-Juhany LI (2010) Degradation of date palm trees and date production in Arab countries: causes and rehabitation. Aust J Basic Appl Sci 4(8):3998-4010

Fu Z, Kawaguchi Y (2015) A short review on drag-reduced turbulent flow of inhomogeneous polymer solutions. Adv Mech Eng 5(1): $1-12$

Ghannam MT, Esmail N (2006) Flow enhancement of medium-viscosity crude oil. J Pet Sci Technol 24(8):985-999

Hart A (2014) A review of technologies for transporting heavy crude oil and bitumen via pipelines. J Pet Explor Prod Technol 4:327-336

Hemant PS, Bharambe DP (2006) Synthesis and evaluation of polymeric additives as flow improvers for Indian crude oil. Iran Polym J 15(12):943-954
Ibrahim RI, Oudah MK, Hassan AF (2017) Viscosity reduction for flowability enhancement in Iraqi crude oil pipelines using novel capacitor and locally prepared nanosilica. J Pet Sci Eng 156:356-365

Khadom AA, Abdul-Hadi AA (2014) Performance of polyacrylamide as drag reduction polymer of crude petroleum flow. Ain Shams Eng J 5:861-865

Langevin D, Poteau S, Hénaut I, Argillier JF (2004) Crude oil emulsion properties and their application to heavy oil transportation. Oil Gas Sci Technol Rev IFP 59(5):511-521

Manfield PD, Lawrence CJ, Hewitt GF (1999) Drag reduction with additives in multiphase flow: a literature review. Multiphase Sci Technol 11:197-221

Marmy RMS, Hayder AB, Rosli MY (2012) Improving the flow in pipelines by Cocos nucifera fiber waste. Int $\mathrm{J}$ Phys Sci 7(26):4073-4080

Nunez G, Briceno M, Mata C, Rivas H, Joseph D (1991) Flow characteristics of concentrated emulsions of very viscus oil in water. J Rheol 40:405-423

Pereira AS, Andrade RM, Soares EJ (2013) Drag reduction induced by flexible and rigid molecules in a turbulent flow into a rotating cylindrical double gap device: comparison between poly (ethylene oxide), polyacrylamide, and xanthan gum. J Non Newtonian Fluid Mech 202:72-78

Pierre C, Barré L, Pina A, Moan M (2004) Composition and heavy oil rheology. Oil Gas Sci Technol Rev IFP 59(5):489-501

Pouranfard AR, Mowla D, Esmaeilzadeh F (2014) An experimental study of drag reduction by nanofluids through horizontal pipe turbulent flow of Newtonian liquid. J Ind Eng Chem 20:633-637

Ram A, Finkelstein E, Elata C (1967) Reduction of friction in oil pipelines by polymer additives. Ind Eng Chem Process Des Dev 6(3):309-313

Salman A, El Shargi MK, Al-Habsi SR (2016) New concept of utilization of dates palm trees byproducts in ruminants feeding. Presented in the proceedings of the Conference on the Investment in Date Palm Sector (Reality and Prospects), Diwan of Royal Court, Sultanate of Oman. 23-25 May, 2016. https://mdp.gov.om/asset s/site/downloads/last-report.pdf. Accessed 2018

Speight JG (Ed.) (1998) Petroleum chemistry and refining, Taylor \& Francis, Routledge

Trinh KT (2017) On the Blasius correlation for friction factors. Institute of Food Nutrient Human Health, Massey University, New Zealand. https://arxiv.org/ftp/arxiv/papers/1007/1007.2466.pdf

Usman AR, Abduljabbar A, Vithanage M, OK YS, Ahmed M, Elfaki J, Adulazeem SS, Al-Wabel MI (2015) Biochar production from date palm waste: carrying temperature induced charges in composition and surface chemistry. J Anal App Pyrolysis 115:392-400

Wardhaugh LT, Boger DV (1991) Flow characteristics of waxy crude oils: application to pipeline design. AIChE J 37(6):871-885

Zakin JL, Lu B, Bewersdorff H-W (1998) Surfactant drag reduction. Rev Chem Eng 14:253-320

Publisher's Note Springer Nature remains neutral with regard to jurisdictional claims in published maps and institutional affiliations. 